ISSN 1518-3483

Licenciado sob uma Licença Creative Commons

(c) (1)

\title{
A formação docente e o ensino de História e Geografia no contexto dos anos iniciais do ensino fundamental
}

Teacher education and History and Geography teaching in the context of the early years of elementary school

La formación docente y la enseñanza de Historia y Geografía en el contexto de los años iniciales de la enseñanza primaria

Maria Iolanda Monteiro*

Universidade Federal de São Carlos (UFSCar), São Carlos, SP, Brasil

\section{Resumo}

O artigo refere-se a uma pesquisa realizada com 45 professores dos anos iniciais do ensino fundamental da rede pública, em 2009, pertencentes à região de Araraquara, Estado de São Paulo. $\mathrm{O}$ estudo buscou o entendimento das dificuldades sobre o ensino e conteúdo 
de História e Geografia. Utilizou-se a entrevista para a sistematização dos dados, com orientações da pesquisa qualitativa. O estudo possibilitou a definição de algumas diretrizes para as políticas públicas de formação de professores, como valorização das áreas de História e Geografia, apropriação de seus conteúdos escolares e desenvolvimento de um estilo de ensino para o trabalho interdisciplinar. Identificaram-se ainda questões que envolvem a problemática da rotatividade docente nas escolas e do projeto político pedagógico da escola com espaços reservados para as áreas em discussão.

Palavras-chave: História. Geografia. Política pública de formação.

\begin{abstract}
The article refers to a survey of 45 teachers of the early years of elementary public education carried out in 2009, belonging to the region of Araraquara, São Paulo. The study sought to understand the difficulties about teaching and contents of History and Geography. We used the interview to the data systematization with the guidelines of qualitative research. The study allowed defining some guidelines for public policies of teacher education, as valorization of History and Geography fields, ownership of their school curriculum and developing a style of teaching for interdisciplinary work. It also identified issues surrounding the problem of teacher turnover in schools and the political pedagogical project of the school with agenda for the areas under discussion.
\end{abstract}

Keywords: History. Geography. Public policy of Education.

\title{
Resumen
}

El artículo se refiere a una investigación realizada con 45 profesores de los años iniciales de la enseñanza primaria de la red pública, en 2009, que hacen parte de la región de la ciudad de Araraquara, provincia de San Pablo. El estudio tuvo como intento la comprensión de las dificultades acerca de la enseñanza y contenido de Historia y Geografía. Se utilizó de la entrevista para sistematizar los datos, con orientaciones de la investigación cualitativa. 
El estudio posibilitó la definición de algunas directrices para las políticas públicas de formación de profesores, como valoración del área de Historia y del área de Geografía, apropiación de sus contenidos escolares y desarrollo de un estilo de enseñanza para el trabajo interdisciplinar. Aún se identificaron cuestiones que involucran la problemática de la alternancia docente en las escuelas y del proyecto político pedagógico de la escuela con espacios destinados a las áreas en discusión.

Palabras clave: Historia. Geografía. Política pública de formación.

\section{Introdução}

As pesquisas na área da Educação elucidam o aumento significativo da presença de discussões sobre formação de professores, cujo tema, conforme André (2011), relacionava-se, antes da década de 90, ao campo de estudos da Didática. Para a autora, a temática formação de professores cresceu também nas publicações dos periódicos científicos, incluindo números especiais e/ou seções voltadas exclusivamente à temática.

Com o objetivo, então, de contribuir para as discussões a respeito da profissão docente dos anos iniciais do Ensino Fundamental, realizou-se uma pesquisa com professores para o entendimento das características do trabalho pedagógico e dos conteúdos curriculares de História e Geografia. Nessa perspectiva, tornou-se possível a identificação de aspectos na formação profissional, que deveriam ter sido cultivados nos cursos de formação de educadores. No ano de 2013, foi desenvolvida uma investigação com 45 docentes dos anos iniciais do Ensino Fundamental, pertencentes à região de Araraquara, Estado de São Paulo, sendo 44 professoras e um professor. Todas as escolas envolvidas estavam organizadas, conforme as especificidades do Ensino Fundamental de Nove Anos (BRASIL, 2006. Todas as escolas pertenciam à rede estadual ou municipal de ensino.

Utilizou-se a pesquisa qualitativa (LÜDKE; ANDRÉ, 1986) com o objetivo de pensar o ensino de História e Geografia a partir da análise 
da formação e atuação profissional. Os dados foram coletados por meio de entrevista sobre as principais dificuldades dos professores, relacionadas ao ensino e conteúdo dos anos iniciais do Ensino Fundamental.

Os dados referentes à formação profissional dos professores revelaram que todos os participantes (45) fizeram o curso de Licenciatura em Pedagogia, 10 realizaram o curso de Magistério, oferecido no Ensino Médio, três concluíram a pós-graduação de lato sensu e uma cursou outra graduação (Letras), além da Pedagogia. Quanto à experiência, todos os docentes exercem a profissão no contexto dos anos iniciais do Ensino Fundamental das escolas públicas e quatro já ministraram aulas na rede particular. Apenas uma professora tem experiência como coordenadora pedagógica e duas na área de Educação Infantil.

Organizou-se uma escala de análise para o mapeamento do tempo de serviço dos participantes na profissão docente, com um intervalo de 10 anos. Os dados revelam que 19 professores entrevistados possuem entre 0 a 10 anos de experiência; 16 docentes entre 10 a 20 anos e 10 entre 20 a 30 anos de magistério. Essa configuração permite afirmar que a maioria das pessoas pesquisadas concluiu recentemente o curso de formação de educadores, considerando a época da entrevista.

Duas questões, referentes às dificuldades sobre o ensino e conteúdo de História e Geografia dos anos iniciais do Ensino Fundamental, nortearam o desenvolvimento da pesquisa. Para o estudo do ensino e conteúdo organizaram-se, a partir das respostas dos participantes, eixos de análise. A apreciação das dificuldades sobre o conteúdo foi constituída por três eixos: Especificidades dos materiais didáticos; Redução da carga horária das disciplinas História e Geografia e Natureza de conteúdo. O eixo Especificidades dos materiais didáticos engloba respostas referentes aos materiais didáticos e à avaliação sobre o livro didático das respectivas áreas. No eixo Redução da carga horária das disciplinas História e Geografia, qualifica-se o posicionamento dos participantes a respeito da articulação entre a quantidade de conteúdo e a carga horária das áreas de conhecimento. O último eixo Natureza de conteúdo revela os conteúdos específicos das disciplinas, tornando-se visível a complexidade de determinados assuntos e de suas especificidades. 
A partir das respostas relacionadas às dificuldades no ensino da História e Geografia, estabeleceram-se três eixos de análise: Relações entre ensino do conteúdo específico e desempenho escolar; Utilização de materiais didáticos; Formação docente. O eixo de análise Relações entre ensino do conteúdo específico e desempenho escolar aborda as relações inerentes ao trabalho pedagógico, utilizado para ensinar os conteúdos específicos, desenvolvidos durante as aulas de História e Geografia, e aos exemplos sobre a repercussão entre a especificidade do ensino e o desempenho escolar dos alunos. No eixo Utilização de materiais didáticos, estão alocadas situações referentes às particularidades dos materiais didáticos, ao uso dos recursos no cotidiano das aulas dessas disciplinas e suas relações com o desempenho do professor e dos alunos. No eixo Formação docente, relacionam-se às características profissionais dos professores participantes, elucidando dificuldades e conflitos pedagógicos desencadeados pela formação.

O resultado do estudo de Monteiro (2008) sobre as representações e dificuldades do trabalho pedagógico de professoras que frequentam os cursos de formação, envolvendo todas as disciplinas dos anos iniciais do Ensino Fundamental, confirma também a presença de situações do trabalho docente que prejudicam a configuração de práticas pedagógicas bem sucedidas. Esta constatação elucida caminhos de investigações sobre a formação do professor dos anos iniciais do Ensino Fundamental.

A discussão a respeito das representações e dificuldades presentes no trabalho docente contribuiu para a própria reflexão das professoras e para suas mudanças relacionadas ao ato de ensinar e à repercussão das práticas. As informações obtidas identificaram aspectos que precisariam ser garantidos nos cursos de formação de professores, como a apropriação de conteúdos e conceitos básicos das áreas de conhecimento, o re(conhecimento) das contribuições dos conteúdos escolares, o desenvolvimento de habilidades mentais específicas das áreas, a condição criativa de atuar com autonomia intelectual e a capacidade de trabalhar com o coletivo (MONTEIRO, 2008, p. 203). 
Essa pesquisa confirma também que os cursos de formação de professores não estão conseguindo preparar o docente para atuar, com autonomia pedagógica, os conteúdos dos anos iniciais.

\section{Principais dificuldades relacionadas ao conteúdo de História e Geografia}

Os eixos de análise da temática "dificuldades nos conteúdos" elucidam situações formativas ligadas, direta ou indiretamente, aos cursos de formação inicial e continuada. No eixo Especificidades dos materiais didáticos, 17 professores manifestaram-se sobre o uso de materiais didáticos, apresentando críticas fundamentadas sobre o livro didático e os projetos organizados pelas Secretarias da Educação do Estado e municípios. Nos dados apareceram respostas diferentes, permitindo a percepção de que a dificuldade pedagógica surge quando o livro didático, por exemplo, aborda apenas um modelo de bairro e família e assuntos pertencentes a outros tipos de contextos, não contribuindo para a identidade da criança nem para o reconhecimento de sua cidadania. A delimitação do conteúdo para o primeiro e segundo ano, a partir do livro didático, apresenta-se de modo frágil, pois alguns conceitos não são abordados nos livros e precisariam ser desenvolvidos para que os alunos pudessem compreender situações específicas de História e Geografia, acontecimentos e relações mais complexas, inerentes ao terceiro ano do Ensino Fundamental.

Conforme os depoimentos, o professor que usa apenas o livro didático para explicar um determinado contexto limita o desenvolvimento do aluno. Isso acontece porque o conteúdo de História e Geografia exige pesquisas constantes para tornar possível uma relação concreta com outras realidades, trabalho com diversas formas e aprofundamento do tema, a partir do conhecimento que o aluno já sabe. Além disso, a dificuldade aparece, quando o conteúdo é imposto pelo livro didático, pois não contextualiza o tempo, espaço nem a vivência do aluno e da sociedade em que vive. É fechado, estático e desconsidera o cotidiano em que o estudante está 
inserido, prejudicando o interesse e envolvimento. Os livros restringem-se, muitas vezes, às datas comemorativas e aos fatos históricos, dificultando a apropriação do conteúdo específico da História e Geografia. Portanto, faz se necessário uma adequação desses conteúdos de modo que se tornem significativos para o aluno, principalmente, dos anos iniciais. É necessário trabalhar o concreto e o lúdico não apenas com os primeiros anos, objetivando levar a criança para o real (BITTENCOURT, 2004b; CALLAI, 2005).

Existem alguns casos em que os conteúdos dos livros e das apostilas, conforme os relatos, têm uma linguagem difícil e, por essa razão, não são utilizados, a não ser para que os alunos realizem cópias, leitura e para mostrar os desenhos, mapas e paisagens. Revelam que muitos conteúdos defendem a cultura dominante, estão errados e ultrapassados, devido à quantidade de informação que os vários canais de comunicação veiculam. Mostram ainda que o complexo não é o conteúdo, mas a linguagem.

Diante do conteúdo de Geografia, identificou-se, nas respostas dos participantes, que se houvesse na escola mapas e globos terrestres atualizados, ou seja, materiais para visualizar as explicações, a compreensão dos alunos seria potencializada. Os conceitos e elementos da Geografia, por exemplo, necessitam muito de materiais visuais, como mapas. Faltam esses materiais na escola, além de outras coisas como vídeos e, sem o auxílio destes materiais, é difícil apresentar tais conteúdos. Já no conteúdo de História, a maior dificuldade está no conflito entre o conteúdo que há nos livros e a verdadeira História do País.

As pesquisas e reflexões sobre o livro didático permitem apreendê-lo em sua complexidade. Apesar de ser um objeto bastante familiar e de fácil identificação, é praticamente impossível defini-lo. Pode-se constatar que o livro didático assume ou pode assumir funções diferentes, dependendo das condições, do lugar e do momento em que é produzido e utilizado nas diferentes situações escolares. Por ser um objeto de "múltiplas facetas", o livro didático é pesquisado enquanto produto cultural; como mercadoria ligada ao mundo editorial e dentro da lógica de mercado capitalista; como suporte de conhecimentos e de métodos de ensino das diversas disciplinas e matérias escolares; e, ainda, como veículo de valores, ideológicos ou culturais (BITTENCOURT, 2004a, p. 1). 
O trabalho de Bittencourt (2004a) sobre o livro didático, de modo geral, explicita relações contraditórias estabelecidas entre o livro didático e a sociedade, pois o conteúdo não revela por meio de suas unidades os condicionantes sociais, prejudicando o entendimento da realidade.

Os projetos que são encaminhados às escolas para o professor desenvolver apresentam ainda, de acordo com as manifestações, um material pronto e fechado, prejudicando a autonomia pedagógica e, consequentemente, o desempenho docente. A escola está mais equipada com tecnologia: data show, internet, lousa digital, paradidáticos, livros, revistas, mapas, etc., o que resulta um excesso de informações. Para os entrevistados, administrar e articular toda essa tecnologia, num contexto com uma grade curricular reduzida, tem se tornado um tormento para os momentos das áreas de História e Geografia.

No eixo Redução da carga horária das disciplinas História e Geografia, apenas seis professores fizeram referência ao prejuízo da redução da carga horária, mostrando que a extensão do conteúdo destas áreas e o período destinado impossibilitam o desenvolvimento de um bom trabalho. A redução da carga horária dessas duas disciplinas na rede estadual ocorreu, por exemplo, para cobrar do professor um maior empenho na Língua Portuguesa e Matemática, mais especificamente por meio do projeto "Ler e Escrever", o qual dá pouquíssima abertura para a contextualização de História e Geografia.

O conteúdo de História e Geografia é muito abrangente e extenso e prejudica o trabalho docente, pois o professor precisa, de acordo com as entrevistas, fazer seleções que cingem competências e habilidades que contemplem a maior parte possível do conteúdo curricular indispensável e adequar as situações de aprendizagem à realidade do educando.

A Resolução SE $n^{\circ} 10$, de 28-1-2010, altera o $\S 4^{\circ}$ do art. $3^{\circ}$, o $\S 5^{\circ}$ do art. $5^{\circ}$ e o Anexo I da Resolução SE n ${ }^{\circ} 98$, de 23 de dezembro de 2008 (SÃO PAULO, 2010), que estabelece diretrizes para a organização curricular do Ensino Fundamental e do Ensino Médio nas escolas estaduais do Estado de São Paulo, institui para os quartos e quintos anos do Ensino Fundamental de nove anos ou para as terceiras e quartas séries do 
Ensino Fundamental antigo, as disciplinas de História e Geografia. Essa normativa acaba prejudicando a formação do aluno crítico desde os dois primeiros anos, pois a própria lei não assegura espaços para o desvendamento das máscaras sociais e a identificação dos condicionantes sociais.

A própria Resolução $n^{\circ} 2$, de $1^{\circ}$ de julho de 2015 (BRASIL, 2015) não faz referência ao ensino e conteúdo de História e Geografia, apresentando diretrizes genéricas e ambiguidade em alguns períodos do documento. O respectivo material não faz parte do momento histórico e político das entrevistas, mas mesmo assim mostra o tipo de orientação formativa que o professor acaba recebendo.

A análise dos depoimentos dos educadores, alocados no eixo sobre a redução da carga horária, revela que os conteúdos dos quintos anos poderiam ser simplificados, priorizando os principais fatos da História e Geografia, pertencentes aos alunos. Saber selecionar o conteúdo extenso é uma grande dificuldade. O maior desafio, principalmente no início da profissão, é selecionar o que desenvolver com os alunos a partir de um tempo previsto. Torna-se muito complexo trabalhar o conteúdo de História e Geografia em uma ou duas aulas por semana, conforme orientação da Secretaria da Educação. Se essas disciplinas fossem apresentadas numa organização integrada às outras disciplinas e trabalhadas desde o primeiro ano, o ensino atenderia a especificidades das áreas sem prejudicar os resultados bem-sucedidos.

Pelos estudos sobre formação docente (MONTEIRO, 2008; 2010) e pela pouca manifestação dos professores investigados a respeito das implicações da redução da carga horária, confirma a urgência de rever a função do professor dos anos iniciais do ensino fundamental e a contribuição da natureza de cada conteúdo e sua complexidade.

O último eixo Natureza de conteúdo abrangeu 28 respostas relacionadas às especificidades do conteúdo de História e Geografia, mostrando suas exigências e especificidades para o contexto dos anos iniciais do ensino fundamental. A natureza do conteúdo dessas disciplinas para os participantes da pesquisa exige, do professor, investigações constantes. O conteúdo deve chegar à sala pelo próprio aluno, por meio de pesquisas, 
objetos, documentos impressos, livros, revistas, jornais, entrevistas, documentários e filmes, visando uma organização coletiva. As dificuldades em História são maiores ao comparar com o conteúdo de Geografia, pois nesta área o professor consegue mostrar rio, vegetação e relevo com características diferentes.

Conforme os depoimentos, para demonstrar os aspectos de uma outra época, é necessário mostrar fotos e objetos, levar os alunos aos museus, cuja prática no contexto das escolas públicas brasileiras é escassa, pois no Brasil as pessoas não têm ainda este costume nem uma lei pública que garanta essas experiências extraescolares. Desde os Parâmetros Curriculares Nacionais de História e Geografia (BRASIL, 2000), verifica-se a necessidade de ocorrerem situações pedagógicas para o entendimento das especificidades da área, objetivando a construção de noções históricas, por meio da diversificação das fontes de informações.

Os participantes afirmaram ainda que as práticas de ensino heterogêneas permitem aos alunos perceberem, com mais facilidade, que o passado ainda está no presente e que foi por meio deste passado que o presente foi construído. Os assuntos relacionados ao império ou à colônia não são considerados interessantes pelos estudantes e, consequentemente, são difíceis de serem desenvolvidos, pois não conseguem perceber a relação com o mundo em que eles vivem atualmente. Por essa razão, a apropriação do conteúdo se torna maçante e desinteressante, solicitando, assim, do professor recursos didáticos e linguísticos para a organização de um trabalho mais dinâmico e concreto.

É confuso para as crianças compreenderem suas vidas tais como são hoje e como se deram essas transformações, ao longo dos anos, reconhecendo que tudo já foi diferente. Na Geografia, fica muito complexo organizar uma explicação sobre meio ambiente, saneamento básico, mapas, hidrografia, localizações, regiões diferentes do País, altitude e pontos cardeais sem ter como mostrar de uma forma mais real e palpável. $\mathrm{O}$ estudo e a interpretação dos dados de mapas exigem do aluno uma capacidade de abstração. Além disso, a ausência de familiaridade do estudante com a linguagem cartográfica emperra o entendimento. Os conteúdos são 
muito difíceis de serem trabalhados com crianças que ainda não escrevem direito. Essa situação mostra a necessidade de o professor mudar a sua estratégia metodológica para despertar o interesse dos alunos, adotando práticas de ensino mais dinâmicas, como: rodas de conversas, maquetes, mapas e globo terrestre (BRASIL, 2000).

Recorre-se ao estudo de Moreira (2007) para ressaltar a necessidade dos professores entrevistados superarem a concepção apresentada. $\mathrm{O}$ trabalho do autor caracteriza a renovação da Geografia brasileira no período de 1978-1988, que revela a importância de "pensar e ser em geografia":

Duas fases distinguem-se no movimento de renovação. A primeira situa-se no período imediatamente anterior e posterior ao $3 .{ }^{\circ} \mathrm{ENG}^{1}$, reunindo os anos de virada das décadas de 1970-80. É a fase das mudanças mais efetivas, fase da crítica que indaga sobre o sentido e significado do discurso geográfico ("o que é, para que serve e para quem serve a geografia"), renovando onde era possível. A segunda situa-se a partir da segunda metade da década de 1980. É a fase em que a renovação vira uma oficialidade (uma "geografia crítica"), muda o ritmo e o sentido de rumo e assim confunde sua primazia e se consome nessa mudança (MOREIRA, 2007, p. 36).

Verifica-se, assim, nos depoimentos dos participantes a presença destas duas concepções de Geografia. Alguns trabalham com os aspectos da Geografia Física e outros com situações que caracterizam interpretações e posicionamentos críticos. Os conteúdos para as turmas de primeiros e segundos anos, de acordo com os relatos, se apresentam como muito abstratos, principalmente, no momento em que o docente vai trabalhar com questões que irão preparar o aluno para ler e pensar o mundo que está a sua volta, tornando o conteúdo significativo. Apesar desta comprovação, percebem a relevância dos aspectos que levam o aluno a pensar o mundo com criticidade.

1 Refere-se ao Encontro Nacional de Geografia. 
$\mathrm{Na}$ disciplina História, é muito difícil expor um tempo muito longe e realidades distantes das crianças, mesmo relatando os anos dos fatos. Para os participantes, muitas não têm a dimensão do tempo. Outra dificuldade visível é a continuidade dos fatos, pois as crianças não conseguem ligar um acontecimento a outro, ou mesmo entender que, durante o período em que ocorreu uma situação no Brasil, aconteceram outras no resto do planeta.

Para os participantes, quando se trata do passado, envolvendo a História Antiga, por exemplo, é difícil fazer com que os alunos liguem a época, o lugar e os fatos. Não conseguem associar ou perceber que existe uma correspondência com o mundo atual, nem entender a importância do estudo das relações entre o Homem e seu tempo, não se reconhecendo na História. Nessa perspectiva, questiona-se, então, como uma criança que reconhece a disciplina como uma sequência de fatos pode se perceber como sujeito ativo dessa História, localizando-se em seu tempo e espaço?

A partir, então, da análise da natureza desses conteúdos identificados pelos participantes, percebe-se que as crianças têm muita dificuldade em assimilar a transformação do mundo e as mudanças na realidade. Essa situação é amenizada, quando o professor explica o conteúdo de História e Geografia, trazendo para a contemporaneidade, ou seja, quando faz o cotejo entre as áreas para garantir o significado da aprendizagem do assunto abordado.

As declarações dos docentes explicitam que o trabalho pedagógico envolvendo identidade do aluno, seu bairro, pessoas com que convive, História da família, características da natureza de seu meio ambiente, construção de maquetes com produtos recicláveis, rodas de conversas, atividades práticas, estudo do meio, pesquisas temáticas e entrevistas com avós e pais, assegura o envolvimento da turma de alunos e sua aprendizagem. Do mesmo modo, a utilização de filmes e documentários, complementados por passeios, auxilia o estudo dos conceitos geográficos e históricos, ganhando autonomia diante das diretrizes do livro didático e das propostas dos órgãos oficiais. 
Igualmente, as respostas dos participantes sobre a dificuldade de selecionar o conteúdo para cada aula, visando a continuidade, durante o ano letivo, e de encontrar exercícios que ajudem os alunos na compreensão e fixação do conteúdo, sinalizam a necessidade de projetos interdisciplinares, conforme Fazenda (1998), envolvendo, sobretudo, essas duas disciplinas e a participação de todos os professores da escola. Esses projetos precisariam considerar em seus objetivos a própria dificuldade dos alunos nas práticas da leitura e escrita, pois a falta destes acaba emperrando a apropriação dos conteúdos de História e Geografia.

\section{Principais dificuldades relacionadas ao ensino de História e Geografia}

Diante da análise das entrevistas, verificou-se que as respostas de 35 participantes relacionaram-se ao eixo Relações entre ensino do conteúdo específico e desempenho escolar, pois fizeram referência às particularidades do ensino dos conteúdos peculiares no cotidiano das aulas de História e Geografia, ressaltando a repercussão entre o ensino e desempenho escolar dos alunos. Identificou-se que a dificuldade para ensinar Geografia é maior do que ensinar História, pois é mais fácil fazer uma contextualização com outras áreas de conhecimento, como Português e Matemática. A dificuldade para os participantes está em encontrar um tema e uma maneira de ensinar que desperte o interesse dos alunos, considerando os temas do convívio da criança, e articular os assuntos com outras matérias e o conhecimento antigo com a realidade do educando, visando a transposição do conhecimento científico para os fatos da atualidade. A dificuldade aparece quando o ensino não parte do dia a dia do aluno.

Conforme os entrevistados, quando os alunos vão associar os espaços geográficos naturais e artificiais "mais subjetivos" e conteúdos que exigem uma maior abstração para o acompanhamento da dinâmica e sequência da aula, não conseguem bons resultados. O problema é intensificado com as crianças do primeiro ano do ensino fundamental. Quando um conteúdo que depende da imaginação é desenvolvido pelo professor, 
como por exemplo planície ou o planalto e, principalmente em relação à Geografia Física do Brasil, os alunos apresentam certa dificuldade. Isso acontece porque o ensino ocorre por meio de explicações que não são complementadas por recursos concretos e visitas a locais específicos da realidade do aluno ou sobre os temas trabalhados, acarretando a articulação da teoria e prática e, consequentemente, o entendimento.

Outras situações, pertencentes também aos outros anos do ensino fundamental, que prejudicam o trabalho com a Geografia referem-se aos alunos que não possuem conhecimento geográfico básico, não sabem realizar localizações simples e aqueles que memorizam os conteúdos da Geografia, por acreditarem que essa disciplina não permite outro procedimento de estudo. Os entrevistados, ainda, elucidaram que as maiores dificuldades aparecem no ensino da diferença espacial, de nomenclatura e dos conceitos de cidade, das características do Estado e País e com a distinção entre caravelas e navios. Essas particularidades revelam a carência de situações pedagógicas que habilitem o aluno a ser agente transformador do espaço.

O ensino de História, para os participantes, requer a desconstrução, muitas vezes, de concepções sobre as especificidades desta disciplina, pois encontram alunos considerando que a História aborda apenas assuntos do passado e datas, que é preciso decorar e não entender, deixando a sensação de que professor e alunos não fazem parte da área. Como consequência, torna-se difícil convencer que todas as pessoas pertencem e fazem História. As questões ligadas à História são desinteressantes para os estudantes quando estão situadas em um passado bem distante. A maior dificuldade é situar a criança no espaço, ou seja, no concreto. Sentem dificuldade quando o tema discute a direção, a ordem cronológica das datas e do tempo histórico.

No ensino de história existe uma significativa dificuldade de trabalhar a compreensão da heterogeneidade do mundo em mudança, por meio da apreensão da multiplicidade de tempos e contextos culturais. Em decorrência dessas circunstâncias, o professor não consegue lecionar de forma a apresentar uma interpretação ampla e diversificada da sociedade 
e reminiscência consciente ao passado coletivo, numa perspectiva crítica e histórica, nem para superar a perspectiva machista, eurocêntrica e racista, desmitificando rótulos e ideias cristalizadas.

Nas disciplinas História e Geografia, o docente não consegue ressaltar a importância do conteúdo, nem realizar o cotejo entre o passado e presente para mostrar suas repercussões, a importância e o possível crescimento pessoal. Os alunos consideram as disciplinas maçantes e tediosas, acarretando o alargamento dos conteúdos e sua apropriação. O próprio conhecimento dos alunos que vivem apenas em sua comunidade se configura como um fator, conforme os depoimentos dos professores, que impede outras interpretações e análises. Como consequência, os alunos não percebem a contribuição das disciplinas nem ficam interessados para a apropriação do conteúdo.

A questão da falta de recurso e as características familiares apareceram também nas duas disciplinas, pois a deficiência de jornais, revistas e livros para pesquisar e a presença de pais não leitores prejudicam o andamento do ensino. Para os participantes, a bagagem cultural restrita dos educandos, ou seja, crianças desprovidas de capital cultural, bem como ausência de participação e envolvimento familiar nas atividades propostas, obstina a evolução da aprendizagem dos alunos. Na maioria das vezes, a criança precisa ir ao lugar e ver de perto as especialidades das paisagens e dos lugares (CALLAI, 2005; MOREIRA, 2007).

Com relação ainda ao campo familiar, alguns participantes afirmaram que a organização de atividades para envolver a família nas questões ambientais e culturais poderia contribuir para o rendimento escolar dos alunos. Explicitaram também que a falta de veemência dos alunos pelos conteúdos de História e Geografia, a incapacidade para a organização do ensino de determinados conteúdos, de diversificar a prática pedagógica, a dependência do livro didático que, em alguns casos, apresenta uma realidade diferente daquela vivida pelos alunos, aferram a desenvoltura docente.

A opção do professor pelo ensino dos conteúdos das disciplinas História e Geografia e pelo livro didático acaba não contribuindo para despertar o interesse de alguns alunos em relação às disciplinas que, 
muitas vezes, trazem conteúdos com explicações sistematizadas de forma complexa. Essa característica, para os participantes, impede a criança com dificuldade de compreender o conteúdo, ao realizar a leitura sozinha, acirrando, principalmente, no momento da tarefa de casa, das pesquisas e situações em que o professor não está perto para auxiliá-la. Além disso, o ensino que exige reflexão sobre os acontecimentos cotidianos e do mundo, solicitando problematizações concretas para o encontro de soluções possíveis, não fluem, pela ausência de uma preparação dos alunos para essa natureza de prática pedagógica. Os professores não conseguem convencê-los a respeito da possibilidade destas disciplinas desencadearem o desenvolvimento cultural de todos. Desenvolver a visão crítica dos fatos e levar o aluno a refletir a partir dos conteúdos de História e Geografia, apresentam-se com desafios constantes para os docentes.

Outros desafios nestas disciplinas referem-se ao ensino que envolve relações entre diferentes identidades e contextos, entendimento de ações passadas e presentes, análise da realidade na qual o aluno está inserido, percepção de momentos de permanência e rupturas nas diferentes esferas sociais e aspectos pertencentes ao cotidiano, possibilitando uma reflexão sobre sua realidade e de outras distantes. A garantia da compreensão sobre sociedades, nações de temporalidade e espaços diversos e a capacidade de atribuir significado aos conhecimentos adquiridos pelos alunos configuram-se como dificuldades complexas para o professor.

Nos primeiros anos, em salas de alfabetização, muitas crianças ainda não dominam bem a linguagem escrita, exigindo outro tipo de postura didática, principalmente, nas disciplinas História e Geografia. Portanto, as aulas são realizadas em maior tempo por meio da oralidade, sendo registradas pelo professor. Nos anos seguintes de escolarização, a maior dificuldade relaciona-se à lacuna de formação na área da leitura e escrita. As crianças que ainda não estão alfabetizadas são casos difíceis para o trabalho da leitura e produção dos textos, conforme as entrevistas. Para Cagliari (2010, p. 106), "a produção de um texto escrito envolve problemas específicos de estruturação do discurso, de coesão, de 
argumentação, de organização das ideias e escolha das palavras, do objetivo e do destinatário do texto etc.".

Além destas questões envolvendo as fragilidades das práticas de leitura e escrita, pelos depoimentos, percebe-se que os alunos apresentam uma dificuldade de outra natureza, que se refere à leitura mais elaborada, ou seja, uma leitura que exige a decodificação de conhecimentos de forma bem detalhada para que tomem consciência do tema abordado.

Os alunos despreparados para interpretação de textos, livros, filmes, jornais e revistas, que não se dedicam à leitura, não sabem os significados de várias palavras e mostram pouco interesse em ampliar seu vocabulário e, também, não realizam a apropriação de conteúdos e conceitos inerentes às áreas de História e Geografia. Em decorrência, o próprio professor não apresenta um ensino que atenda as particularidades das disciplinas.

A pouca fluência na leitura dos alunos, de acordo com estudos de Cagliari (2010) e Monteiro (2010), inviabiliza o ensino das disciplinas de História e Geografia. Nos primeiros e segundos anos tem que se trabalhar mais com exemplos concretos, trabalhar o conteúdo por meio do lúdico, com situações próximas à criança. Ainda nos terceiros e quartos anos, o ensino de fatos históricos é muito distante da realidade dos alunos. Se o docente adotar apenas o livro para a explicação destes conteúdos, os alunos acabam decorando. O material concreto e diversificado assegura, possivelmente, a complexidade dos conceitos. Os depoimentos ilustram, assim, a necessidade de ocorrerem mudanças na dinâmica das aulas e na própria natureza das atividades e avaliações bimestrais, evitando a solicitação de conhecimentos decorados.

Os alunos do primeiro e segundo ano do ensino fundamental, que não tiveram História e Geografia, chegam ao terceiro ano sem noção de espaço e tempo o que, para os participantes da pesquisa, dificulta o trabalho envolvendo as regiões geográficas, História do Brasil e localização dos planetas, por exemplo.

No eixo Utilização de materiais didáticos, seis respostas dos entrevistados que referenciaram situações sobre as particularidades dos materiais didáticos foram selecionadas. As respostas revelaram que no início da 
carreira há necessidade de um material de apoio, como cartilha e livro didático. A falta de recursos, como biblioteca, livros e internet, a presença de atlas antigos, ultrapassados e pequenos, a quantidade insuficiente de globo terrestre e a escassez de materiais e recursos financeiros para excursões e visitas aos locais em questão, impedem o aparecimento de práticas de ensino mais dinâmicas e consolidadas. São situações pedagógicas que contribuiriam para o desempenho do professor e, consequentemente, do aluno.

No eixo Formação docente, quatro entrevistados explicitaram respostas inerentes às características formativas, revelando que as dificuldades para ensinar os conteúdos específicos e os conflitos pedagógicos são desencadeados pela formação profissional com lacunas. Conforme os relatos, muitos professores não têm preparação para o ensino de História e Geografia e, portanto, trabalham os conteúdos de modo decorado e automático, o que resulta no desinteresse do aluno pelas respectivas disciplinas. A formação de professores não supre a necessidade que essas áreas exigem. O docente tem a noção de que está desenvolvendo com os alunos, mas não tem o conhecimento aprofundado do campo.

\section{Considerações finais}

O estudo das informações a partir dos eixos de análise possibilitou a identificação de subsídios para as políticas de formações inicial e continuada de educadores. Os professores investigados têm clareza sobre a importância dos conteúdos das disciplinas História e Geografia, mas desconhecem sua contribuição para a formação de cidadãos. Reconhecem a importância de documentos oficiais e do projeto político pedagógico da escola para a orientação do trabalho docente, incluindo a seleção dos conteúdos de acordo com o nível de escolarização. Os professores mostraram que podem seguir as orientações, mas precisariam ter uma formação profissional com uma pedagogia autônoma, que não os limitasse às referências oficiais. 
As fragilidades de certas questões profissionais são acirradas, quando se identifica a ausência de trabalhos focalizando e priorizando os conteúdos e as contribuições das respectivas disciplinas desde a Educação Infantil. Além disso, a cultura organizacional das escolas revela que os projetos políticos pedagógicos valorizam pouco as disciplinas História e Geografia, assegurando, principalmente, espaços coletivos de discussão voltados mais para as áreas de Matemática e Língua Portuguesa. Esse tipo de postura reforça, entre a comunidade escolar, que as outras disciplinas não são importantes. Em decorrência, os professores acabam minimizando suas contribuições e dotando práticas que provocam o esvaziamento do conteúdo. Os próprios alunos expõem ideia de que essas disciplinas são maçantes e exigem muito do estudante.

Pode-se justificar a baixa frequência de resposta no eixo Formação docente, pois muitas respostas alocadas nos outros eixos de análise, de certo modo, relacionam-se, direta ou indiretamente, com as especificidades da profissão de professor. Os resultados da entrevista revelaram que os cursos de formação inicial e continuada não estão atendendo as exigências inerentes ao domínio dos conteúdos das áreas em foco nem os conteúdos de ensino.

As questões referentes às Diretrizes Curriculares Nacionais para a Educação das Relações Étnico-Raciais e para o Ensino de História e Cultura Afro-Brasileira e Africana (BRASIL, 2004) não fizeram parte das discussões e análises dos professores entrevistados. Essa verificação explicita que os cursos de formação inicial e continuada de educadores não atendem essas necessidades formativas.

A pesquisa possibilitou ainda a sistematização de algumas diretrizes para as políticas públicas de formação de professores, como valorização das áreas de História e Geografia, apropriação de seus conteúdos escolares e desenvolvimento de um estilo de ensino para o trabalho interdisciplinar focando as disciplinas. Outras demandas que não se relacionam diretamente com os cursos de formação, mas que dependem de políticas públicas. Estas envolvem questões que incluem a rotatividade 
docente nas escolas e o projeto político pedagógico da escola com espaços reservados para as áreas em discussão.

\section{Referências}

ANDRÉ, M. E. D. A. de. Professores: tensões e perspectivas do campo. In: FONTOURA, H. A. da; SILVA, M. (orgs.). Formação de Professores, Culturas: desafios à Pós-graduação em Educação em suas múltiplas dimensões/ e Rio de Janeiro: ANPEd Nacional, 2011. Disponível em: <http://www.fe.ufrj.br/anpedinha2011/ livro2.html>. Acesso em: 4 set. 2015.

BITTENCOURT, C. M. F. Apresentação. Educ. Pesqui., v. 30, n. 3, p. 471-473, 2004a. Disponível em: <http://www.scielo.br/pdf/ep/v30n3/a07v30n3.pdf〉. Acesso em: 23 de outubro de 2015.

BITTENCOURT, C. M. F. Ensino de História: Fundamentos e Métodos. São Paulo. Editora Cortez, 2004b.

BRASIL. Lei $\mathrm{N}^{\circ} 11.274$, de 06 de fevereiro de 2006. Altera a redação dos arts. 29, 30, 32 e 87da Lei no 9.394, de 20 de dezembro de 1996, que estabelece as diretrizes e bases da educação nacional, dispondo sobre a duração de 9 (nove) anos para o ensino fundamental, com matrícula obrigatória a partir dos 6 (seis) anos de idade. Diário Oficial da União. Brasília, DF, 07 fev. 2006.

BRASIL, Ministério da Educação. Conselho Nacional de Educação. Diretrizes Curriculares Nacionais para a Educação das Relações Étnico-Raciais e para o Ensino de História e Cultura Afro-Brasileira e Africana. Diário Oficial da União de 19/5/2004. Parecer CNE/CP 003/2004.

BRASIL, Ministério da Educação. Conselho Nacional de Educação. Diretrizes Curriculares Nacionais para a formação inicial em nível superior (cursos de licenciatura, cursos de formação pedagógica para graduados e cursos de segunda licenciatura) e para a formação continuada. Diário Oficial da União de 09/7/2015. CNE/CP 002/2015. 
BRASIL. Secretaria de Educação Fundamental. Parâmetros curriculares nacionais: História, Geografia / Secretaria de Educação Fundamental. Brasília: MEC/SEF, 2000.

CAGLIARI, L. C. Alfabetização e linguística. 11.ed. São Paulo: Scipione, 2010.

CALLAI, H. C. Aprendendo a ler o mundo: a geografia nos anos iniciais do ensino fundamental. Cad. Cedes, Campinas, v. 25, n. 66, p. 227-247, maio/ago. 2005.

FAZENDA, I. C. A. A aquisição de uma formação interdisciplinar de professores. In: FAZENDA, I. C. A. (Org.). Didática e interdisciplinaridade. 4. ed. Campinas-SP: Papirus, 1998.

LUDKE, M.; ANDRÉ, M. E. D. A. de. Pesquisa em educação: abordagens qualitativas. São Paulo: Temas Básicos de Educação e Ensino, 1986.

MONTEIRO, M. I. Alfabetização e letramento na fase inicial da escolarização. São Carlos: EdUFSCar, 2010.

MONTEIRO, M. I. Representações e dificuldades do trabalho pedagógico de professoras que freqüentam os cursos de formação. Nuances. Presidente Prudente, SP, ano XIV, v. 15, n. 16, p. 187-205, jan./dez. 2008.

MOREIRA, R. Pensar e ser em geografia. São Paulo: Contexto, 2007.

SÃO PAULO (Estado). Secretaria da Educação. Currículo do Estado de São Paulo: Ciências Humanas e suas tecnologias. São Paulo: SEE, 2010.

Recebido: 02/06/2017

Received: 06/02/2017

Aprovado: 08/07/2017

Approved:07/09/2017 
